\title{
COMUNICAÇÃO
}

\section{GERMINAÇÃO DE SEMENTES DE Dalbergia nigra (Vell.) ALLEMAO EX BENTH. (Fabaceae-Papilionoideae) NO ARMAZENAMENTO}

\author{
Germination of Dalbergia nigra (Vell.) Allemao ex Benth. \\ (Fabaceae-Papilionoideae) during storage
}

\author{
Francismar Francisco Alves Aguiar¹, Armando Reis Tavares², Shoey Kanashiro', \\ Petterson Baptista da Luz ${ }^{3}$, Nelson Augusto dos Santos Júnior ${ }^{1}$
}

\begin{abstract}
RESUMO
Dalbergia nigra (Vell.) Allemao ex Benth. (jacarandá-da-bahia), espécie de alto valor econômico pela qualidade da madeira e potencial ornamental em razão da copa bem formada e à delicadeza da folhagem, está na lista de espécies ameaçadas de extinção. Em função disso, conduziu-se este trabalho, visando à avaliação da qualidade de suas sementes, submetidas a períodos crescentes de armazenamento. Os frutos foram coletados em outubro de 2003, e as sementes armazenadas em geladeira a $6^{\circ} \mathrm{C} \pm 2$, em sacos de plástico transparente fechados. Mensalmente, durante 690 dias, foram retiradas 200 sementes, sendo que 100 foram utilizadas nos ensaios de germinação (quatro repetições de 25 sementes) e 100 para a determinação do teor de água. Os ensaios germinativos foram conduzidos em estufa tipo B.O.D., a $25^{\circ} \mathrm{C}$ e com fotoperíodo de 12 horas. As variáveis analisadas foram a porcentagem de germinação, índice de velocidade de germinação e massa seca das plântulas originadas. Os resultados indicaram que, até 360 dias de armazenamento, as sementes apresentaram porcentagem de germinação próxima de $50 \%$, com redução de cerca da metade do índice de velocidade de germinação, porém, com maior comprometimento do acúmulo da massa seca das plântulas. A porcentagem de germinação inicial e final foram de $87 \%$ e $36 \%$, respectivamente. As sementes de D. nigra têm comportamento ortodoxo e podem ser armazenadas por um período de até dois anos em sacos de plástico a baixa temperatura, com redução em cerca de $50 \%$ de sua capacidade
\end{abstract}

Termos para indexação: Sementes florestais, jacarandá-da-bahia, conservação de sementes, ìndice de velocidade de germinação.

\begin{abstract}
Dalbergia nigra (Vell.) Allemao ex Benth. (Brazilian rosewood) is a highly economically valuable species because of its wood quality and ornamental potential, mainly due to its well formed canopy and the delicacy of its foliage. Unfortunately, these features contributed to list it as an endangered Brazilian species (IBAMA Regulation number 06/92). This work had as its objective to study the quality of Dalbergia nigra seeds submitted to increasing storage periods. Fruits from trees located at the Botanical Institute of Sao Paulo were collected in October 2003. After harvested, the fruits were sun dried and the seeds manually separated. The seeds were stored in closed transparent plastic bags under refrigeration $\left(6^{\circ} \mathrm{C} \pm 2\right)$. Monthly, during 690 days, 200 seeds were removed from the refrigerator. One hundred (100) seeds were used in germination tests, which consisted of four repetitions with 25 seeds each; and the other 100 were used in the determination of water content. The germination tests were conducted in a B.O.D. chamber at $25^{\circ} \mathrm{C}$ under a 12 hour photoperiod. The analyzed variables were; the germination percentage, germination velocity index, and dry mass of the seedlings. The results indicated that after 360 days of storage, the seeds showed germination percentage close to $50 \%$ and reduction of the germination velocity index to half, whereas the dry mass accumulation was the most compromised. The initial and final germination percentages were $87 \%$ and $36 \%$, respectively. We concluded that Dalbergia nigra seeds present orthodox behavior and can be stored for a period of approximately two years in plastic bags at low temperature, compromising $50 \%$ of their germination capacity.
\end{abstract}

Index terms: Forest seeds, jacarandá-da-bahia, seed conservation, germination rate index.

( Recebido em 13 de junho de 2008 e aprovado em 30 de outubro de 2009)

Dalbergia nigra (Vell.) Allemao ex Benth., conhecida popularmente como jacarandá-da-bahia, jacarandá-preto ou caviúna, é uma leguminosa
(Papilionoideae) de porte arbóreo com características de planta semi-heliófita, de ocorrência em Floresta Ombrófila Densa (Floresta Atlântica) (Lorenzi, 1992; Carvalho, 1994).

${ }^{1}$ Instituto de Botânica - São Paulo, SP

2Instituto de Botânica - Cx. P. 3005 - 01061-970 - São Paulo, SP - atavares2005@yahoo.com.br

3Universidade do Estado do Mato Grosso/UNEMAT - Cáceres, MT 
A exploração indiscriminada dessa espécie, em virtude da madeira de ótima qualidade, aliada à devastação de seu ambiente natural, ocasionaram sua inclusão na lista de espécies da flora brasileira ameaçadas de extinção (Brasil, $1992 \mathrm{~b}$; International Union for Conservation of NatureIUCN, 1994). Diante desse quadro, a necessidade de preservação da espécie, bem como sua inclusão nos plantios de reflorestamento, tem se tornado necessárias e demandado dos pesquisadores estudos sobre os diversos aspectos de sua biologia (Carvalho, 1994).

A National Academy of Sciences (1979) destaca o alto valor comercial de $D$. nigra e ressalta a necessidade de informações básicas sobre esse a espécie, iniciando-se pela produção de mudas, espaçamento para o plantio aos estudos de fisiologia sobre a fixação de nitrogênio por bactérias dos pelos nódulos radiculares.

Segundo descrição de Donadio \& Demattê (2000), o fruto de D. nigra é um legume samaróide, seco, indeiscente, glabro, não segmentado e plano; as sementes são estenopérmicas, oblongo-ovaladas, planas, com ápice e base arredondada e superfície glabra. A germinação se inicia rapidamente (Martins \& Silva, 1997) com o intumescimento da semente e, em menos de 10 dias, concomitantemente com o crescimento da raiz, ocorre o desenvolvimento do hipocótilo que logo assume a postura geniculada, tornando-se rapidamente ereta. Andrade et al. (2006) estudaram o efeito do substrato, da temperatura de germinação de sementes de $D$. nigra e o desenvolvimento pós-seminal, observando que a germinação é do tipo faneroepigeal; os cotilédones apresentam função de reserva e sofrem rápida abscisão do hipocótilo. Temperaturas médias de $25^{\circ} \mathrm{C}$ e substratos com alta retenção de água (vermiculita) são os mais adequados para a germinação das sementes da espécie.

As sementes de várias espécies podem ser armazenadas por longos períodos sem tratamento, como muitas leguminosas pioneiras, mas outras necessitam preparação para o armazenamento e condições ambientais especiais. Assim, além do tratamento da própria semente, são necessários embalagem e ambiente apropriados. Os principais meios utilizados para o armazenamento de sementes são: a câmara fria e/ou câmara seca, que se adaptam à maioria das situações (Vieira et al., 2001).

Um dos aspectos mais pesquisados nos últimos anos tem sido a qualidade fisiológica das sementes, em decorrência de estarem sujeitas a uma série de mudanças degenerativas após a sua maturação. Nesse sentido, além das condições ambientais de armazenamento, o tipo de embalagem tem influência significativa na qualidade fisiológica das sementes (Carvalho \& Nakagawa, 2000). A deterioração das sementes de algumas espécies nativas é muito rápida, e o período em que a viabilidade pode ser mantida, varia de algumas semanas a poucos meses, de tal maneira que as pesquisas sobre armazenamento de sementes de espécies florestais nativas assumem caráter de extrema importância (Carneiro \& Aguiar, 1993).

Neste trabalho visou-se à avaliação fisiológica da qualidade de sementes de Dalbergia nigra, após serem submetidas a períodos crescentes de armazenamento.

Os frutos de $D$. nigra foram coletados de matrizes localizadas no Jardim Botânico de São Paulo, em outubro de 2003. Após a colheita, os frutos foram expostos ao sol para a secagem e abertura das vagens, extração manual das sementes e posterior secagem à sombra. O armazenamento das sementes foi feito em saco de polietileno transparente fechados a $6^{\circ} \mathrm{C} \pm 2^{\circ} \mathrm{C}$.

O experimento foi conduzido por período de 690 dias. A cada 30 dias, 200 sementes foram retiradas do armazenamento, sendo que 100 foram destinadas à determinação do teor de água e 100 para o ensaio germinativo (quatro repetições de 25 sementes). $\mathrm{O}$ teor de água foi determinado pelo método de estufa a $105^{\circ} \mathrm{C}$, durante 24 horas (Brasil, 1992a).

O ensaio germinativo foi conduzido em caixa plástica tipo gerbox $(11 \times 11 \times 3,5 \mathrm{~cm})$ transparente com tampa, contendo vermiculita de granulometria média, umedecida com água destilada, sendo mantido em câmara de germinação tipo B.O.D. a $25^{\circ} \mathrm{C}$ e com lâmpada fluorescente com fotoperíodo de 12 horas (Radiação Fotossintéticamente Ativa de $\left.37 \mu \mathrm{mol} \mathrm{m} \mathrm{m}^{-2} \mathrm{~s}^{-1}\right)$. Foram avaliados, ao final de 28 dias, a porcentagem e o índice de velocidade de germinação (IVG), utilizando-se a expressão proposta por Maguire (1962), e a massa seca das plântulas normais (plântulas com o primeiro par de folíolos expandido), após secagem a $70^{\circ} \mathrm{C} \pm 3^{\circ} \mathrm{C}$ até peso constante de matéria seca.

Os dados coletados (quatro repetições de 25 sementes por parcela, sendo cada tratamento constituído pelo número de meses de armazenamento) foram submetidos à análise de variância da regressão, utilizandose o programa estatístico SISVAR (Ferreira, 2000).

A germinação das sementes de Dalbergia nigra decresceu com o decorrer do tempo, variando de $87 \%$ no início a 39\% ao final (690 dias de armazenamento), quando foi atingindo seu menor valor (Figura 1). Os resultados obtidos neste estudo diferem dos de Rego (2001), nos quais afirma que as sementes da espécie perdem sua viabilidade muito rapidamente e qualquer período de armazenamento diminui o percentual de germinação e vigor desta espécie, por serem estas sementes recalcitrantes. 
Figliolia et al. (2001) observaram tendência semelhante para sementes de Caesalpinia peltophoroides Benth., quando a capacidade germinativa inicial das sementes armazenadas em geladeira foi mantida por 360 dias, decrescendo significativamente até $55,6 \%$ aos 640 dias. Resultados semelhantes foram obtidos por Cabral et al. (2003) com sementes de Tabebuia aurea Benth. \& Hook f. ex S. Moore armazenadas em sacos de plástico, em câmara fria e seca, mostrando queda na porcentagem e na velocidade média de germinação, após 150 dias de armazenamento. Aos 150 dias de armazenamento, Scalon et al. (2006), trabalhando com sementes de Jacaranda cuspidifolia Mart., notaram que a porcentagem de emergência alcançou de 76 a 90\%, quando armazenadas à temperatura ambiente e sob refrigeração $\left(12 \pm 2^{\circ} \mathrm{C}\right)$, respectivamente.

Com relação ao índice de velocidade de germinação (IVG), pode-se notar, na análise de variância da regressão, que houve efeito significativo das regressões linear, quadrática e cúbica. Optou-se pela regressão quadrática (Figura 2), por apresentar maior coeficiente de determinação. A regressão mostrou que as sementes de D. nigra germinaram mais lentamente com decorrer do tempo de armazenamento.

Souza et al. (2005), estudando sementes de ipêamarelo, também observaram perda de vigor, com diminuição do IVG, no decorrer do período de armazenamento. Efeito contrário foi observado por Scalon et al. (2006), ao estudarem o armazenamento de sementes de Jacaranda cuspidifolia, que mostraram aumento significativo na taxa de emergência e no índice de velocidade de emergência, quando as sementes foram submetidas ao armazenamento em câmara fria por durante 120 dias.

Segundo Ferraz-Grande \& Takaki (2001), a análise da cinética da germinação de sementes confirma a germinação não sincronizada. A semente de $D$. nigra é insensível à luz e a germinação acima e abaixo da temperatura ótima, indicando que a espécie pode ocorrer tanto na sombra da vegetação bem como em clareiras.

Observou-se efeito significativo nas regressões linear, quadrática e cúbica para a variável massa seca de plântulas (Tabela 1). Optou-se pela regressão cúbica por apresentar maior coeficiente de determinação, conforme a Figura 3, sendo que as plântulas tiveram diminuição da massa seca com o decorrer do armazenamento. Observa-se ainda que houve diminuição da massa seca das plântulas, a partir dos 30 dias de armazenamento, mantendo-se relativamente constante a partir dos 180 dias de armazenamento.

Silva et al. (2001), trabalhando com sementes de Tabebuia heterophylla Britton, mostraram a eficiência da baixa temperatura na conservação das sementes em embalagem impermeável, observando após 489 dias, $86 \%$ de germinação. Segundo Nakagawa (1994), durante a germinação as sementes vigorosas proporcionam maior transferência de massa seca de seus tecidos de reserva para o eixo embrionário, originando plântulas com maior massa seca em razão do maior acúmulo de matéria.

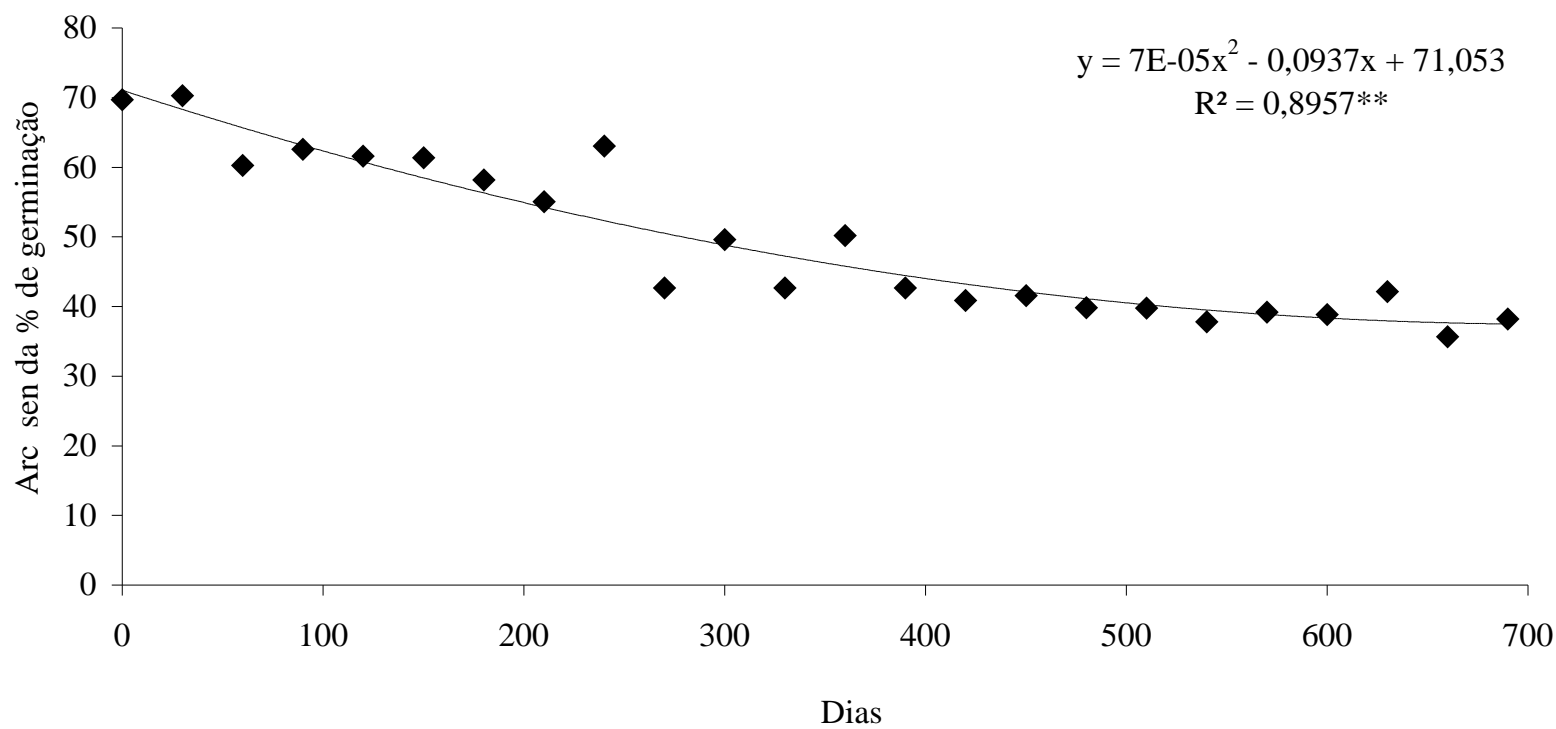

Figura 1 -Médias e função ajustada para a porcentagem de germinação em função dos períodos crescentes de armazenamento das sementes de Dalbergia nigra. IBt, São Paulo, 2004 (**significativo a 1\% de probabilidade). São Paulo, SP, 2003-2005.

Ciênc. agrotec., Lavras, v. 34, Edição Especial, p. 1624-1629, 2010 


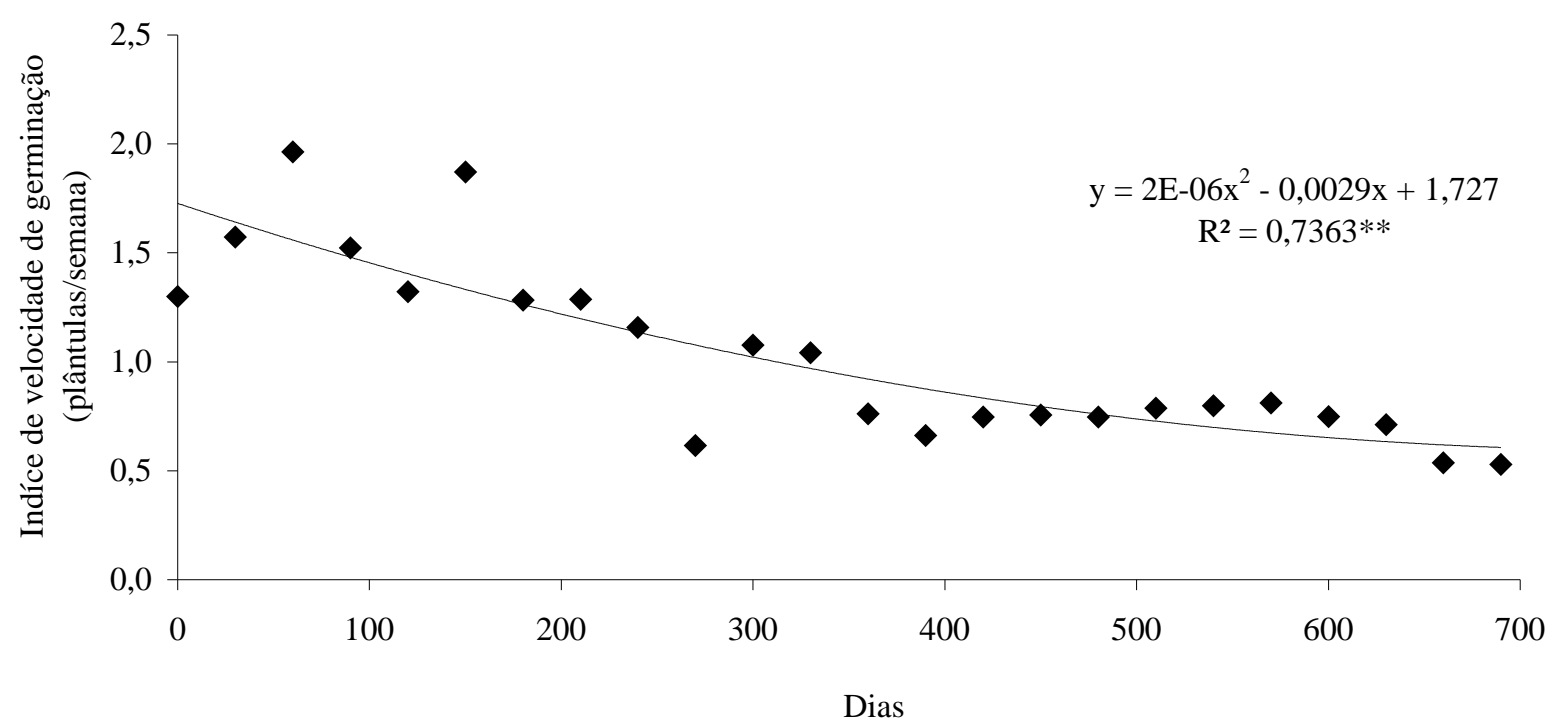

Figura 2 - Médias e função ajustada para o índice de velocidade de germinação (IVG) em função dos períodos crescentes de armazenamento das sementes de Dalbergia nigra (**significativo a $1 \%$ de probabilidade). São Paulo, SP, 2003-2005.

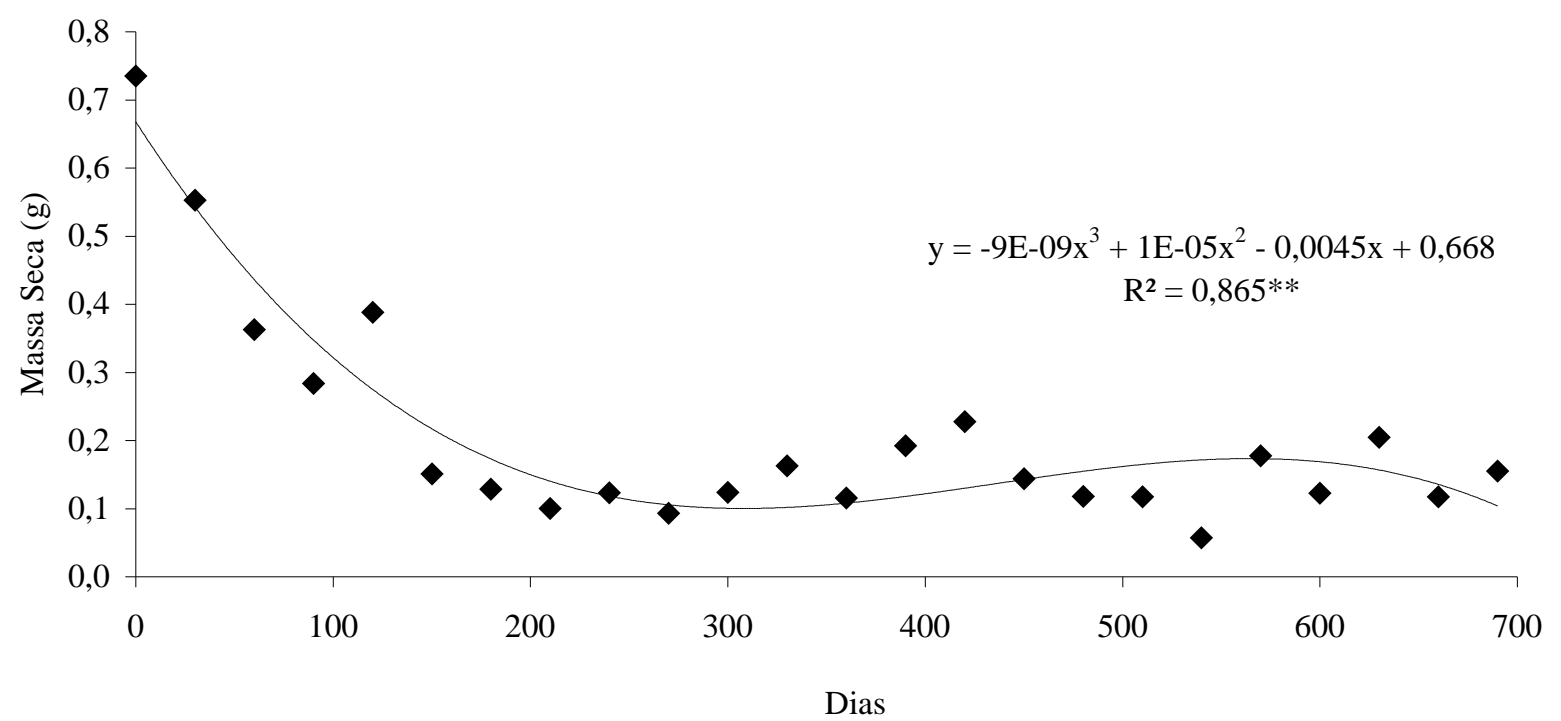

Figura 3 - Médias e função ajustada para a massa seca por plântulas em função dos períodos crescentes de armazenamento das sementes de Dalbergia nigra (**significativo a 1\% de probabilidade). São Paulo, SP, 2003-2005.

Os resultados também mostraram que o teste de germinação foi eficiente na avaliação da qualidade fisiológica das sementes, evidenciada pela alta porcentagem de germinação, IVG e massa seca das plântulas. Os resultados sugeriram que o método de armazenamento de sementes em embalagem de saco de plástico transparente fechado em condições de geladeira foi satisfatório na manutenção da viabilidade de sementes da espécie D. nigra.

As sementes de D. nigra têm comportamento ortodoxo e podem ser armazenadas por um período de até dois anos em sacos de plástico a baixa temperatura, com redução em cerca de $50 \%$ de sua capacidade germinativa. 


\section{REFERÊNCIAS BIBLIOGRÁFICAS}

ANDRADE, A.C.S.; PEREIRA, T.M.; FERNANDES, M. de J.; CRUZ, A.P.M.; CARVALHO, A.S.R. Substrato, temperatura de germinação e desenvolvimento pósseminal de sementes de Dalbergia nigra. Pesquisa Agropecuária Brasileira, Brasilia, v.41, n.3, p.517-523, 2006.

BRASIL. Ministério da Agricultura e Reforma Agrária. Regras para análise de sementes. Brasília: SNDA/ DNDV/CLAV, 1992a. 365p.

BRASIL. Portaria n.006/92-N, de 15 de janeiro de 1992. Lista oficial de espécies da flora brasileira ameaçadas de extinção. Diário Oficial da República Federativa do Brasil, Brasília, p.870-872, 23 jan. 1992b.

CABRAL, E.L.; BARBOSA, D.C. de A.; SIMABUKURO, E.A. Armazenamento e germinação de sementes de Tabebuia aurea (Manso) Benth. \& Hook. f. ex. S. Moore. Acta Botanica Brasilica, São Paulo, v.17, n.4, p.609-617, 2003.

CARNEIRO, J.G.A.; AGUIAR, I.B. Armazenamento de sementes. In: AGUIAR, I.B.; FIGLIOLA, M.B. (Eds.). Sementes florestais tropicais. Brasília: ABRATES, 1993. p.333-350.

CARVALHO, N.M.; NAKAGAWA, J. Sementes: ciência, tecnologia e produção. 4.ed. Jaboticabal: Funep, 2000. 588p.

CARVALHO, P.E.R. Espécies florestais brasileiras: recomendações silviculturais, potencialidades e uso da madeira. Colombo: Embrapa-CNPF; Brasília: EmbrapaSPI, 1994. 638p.

DONADIO, N.M.; DEMATTÊ, M.E.S.P. Morfologia de frutos, sementes e plântulas de canafístula (Peltophorum dubium (Spreng.) Taub.) e jacarandáda-bahia (Dalbergia nigra (Vell.) Fr. All. Ex Benth.) Fabaceae. Revista Brasileira de Sementes, Brasília, v.22, n.1, p.64-73, 2000.

FERRAZ-GRANDE, F.G.A.; TAKAKI, M. Temperature dependent seed germination of Dalbergia nigra Allem (Leguminosae). Brazilian Archives of Biology and Technology, Curitiba, v.44, n.4, p.401-404, 2001.
FERREIRA, D.F. Análises estatísticas por meio do Sisvar para Windows versão 4.0. In: REUNIÃO ANUAL DA REGIÃO BRASILEIRA DA SOCIEDADE INTERNACIONAL DE BIOMETRIA, 45., 2000, São Carlos. Anais... São Carlos: UFSCar, 2000. p.255-258.

FIGLIOLIA, M.B.; SILVA, A. da; AGUIAR, I.B.; PERECIN, D. Efeito do acondicionamento e do ambiente de armazenamento na conservação de sementes de sibipiruna. Revista Brasileira de Horticultura Ornamental, Campinas, v.7, n.1, p.57-62, 2001.

INTERNATIONAL UNION FOR CONSERVATION OF NATURE. International Union for Conservation of Nature and Natural Resources: red list categories. Switzerland: Gland, 1994. 28p.

LORENZI, H. Árvores brasileiras: manual de identificação de plantas arbóreas nativas do Brasil. São Paulo: Plantarum, 1992. 368p.

MAGUIRE, J.D. Speed of germination aid selection and evaluation for seedling emergence and vigour. Crop Science, Madison, v.2, n.2, p.176-177, 1962.

MARTINS, S.L.; SILVA, D.D. Maturação e época de colheita de sementes de Dalbergia nigra (Vell.) Fr. All. ex Benth. Revista Brasileira de Sementes, Brasília, v.19, n.1, p.96-99, 1997.

NAKAGAWA, J. Testes de vigor baseados na avaliação das plântulas. In: VIEIRA, R.D.; CARVALHO, N.M. Teste de vigor em sementes. Jaboticabal: Funep, 1994. p.49-85.

NATIONAL ACADEMY OF SCIENCES. Tropical legumes: resources for the future. Washington, 1979. $331 \mathrm{p}$.

PIÑA-RODRIGUES, F.C.M.; FIGLIOLIA, M.B.; PEIXOTO, M.C. Teste de qualidade. In: FERREIRA, A.G.; BORGHETTI, F. (Orgs.). Germinação: do básico ao aplicado. Porto Alegre: Artmed, 2004. 323p.

REGO, G.M. Ecofisiologia do jequitibá-rosa e do jacarandá-da-Bahia: morfogênese, germinação e crescimento inicial. 2001. 84f. Tese (Doutorado em Produção Vegetal)-Universidade Federal do Paraná, Curitiba, 2001. 
SCALON, S.P.Q.; MUSSURY, R.M.; SCALON FILHO, H.; FRANCELINO, C.S.F.; FLORENCIO, D.K.A. Armazenamento e tratamentos pré-germinativos em sementes de Jacarandá (Jacaranda cuspidifolia Mart.). Revista Árvore, Viçosa, v.30, n.2, p.179-185, 2006.

SILVA, A.; FIGLIOLA, S.B.; AGUIAR, I.B.; PERECIN, D. Liofilização e armazenamento de sementes de ipê-rosa (Tabebuia heterophylla (A.P. Candolle) Britton) -
Bignoniaceae. Revista Brasileira de Sementes, Viçosa, v.23, n.1, p.252-259, 2001.

SOUZA, V.C.; BRUNO, R.L.A.; ANDRADE, L.A. Vigor de sementes armazenadas de ipê-amarelo Tabebuia serratifolia (Vahl.) Nich. Revista Árvore, Viçosa, v.29, n.6, p.833-841, 2005.

VIEIRA, A.H.; MARTINS, E.P.; PEQUENO, P.L.L.; LOCATELLI, M.; SOUZA, M.G. Técnicas de produção de sementes florestais. Porto Velho: Embrapa, 2001. 4p. 